\title{
LEARNING FROM THE NETCOM TRIAL: IMPLICATIONS FOR THE DEPLOYMENT OF RESIDENTIAL BROADBAND NETWORKS ${ }^{10}$
}

\begin{abstract}
Network providers and users have very different views as to how residential broadband networks should be developed. Network providers want to broadcast content to users, but users are interested in developing their own content and in establishing connectivity among peers. This paper discusses the implications of these findings.
\end{abstract}

\section{Introduction}

Research investigating a Canadian residential broadband network trial concluded that consumers and providers have very different visions of how broadband networks should be developed. Consumers demonstrated a preference for using broadband networks as a communication tool, rather than as a means for receiving content. In contrast, the provider organizations in the trial (network and content providers) understood broadband networks as a mechanism for broadcasting content to users, and did not recognize that users found value in the basic connectivity provided by the broadband network.

Given these contradictory perspectives, what shape might future broadband deployments take? How will providers and users interact as broadband connectivity becomes more widely available? This paper offers some preliminary insights on these issues, showing how the provider perspective on broadband success is likely to be challenged by consumer demands for increased control over network content and connectivity.

The paper begins with an introduction to residential broadband networks. It provides a brief overview of the research site and methodology used in the study, summarizes conclusions of earlier research on which this paper is based, and then outlines a series of implications that will impact future residential broadband network deployments.

\section{Residential Broadband Networks}

A residential broadband network can be defined by looking at each term separately. The term network refers to a communication network that uses an information technology-based infrastructure to transmit data from one point to another. The residential nature of the network means that data transmissions either originate from, or terminate at, a consumer's residence. A broadband network is a high capacity network, one that can deliver multimedia transmissions at rapid speeds. A residential broadband network therefore is a high capacity network that can deliver sound, video, high quality graphics, textual information and other data services to consumers in their homes.

\footnotetext{
${ }^{10}$ The author wishes to thank the anonymous reviewers for their detailed and insightful comments on this paper.
} 
There is no real consensus as to how much bandwidth is required for a network to be considered a 'broadband' network (see the National Broadband Taskforce, 2001, on this point). Digital subscriber line (DSL) and cable modem services that offer consumers bandwidths of between 1 and $3 \mathrm{Mbps}$ are generally described as broadband networks, but bandwidths well in excess of 10 Mbps will be required to deliver services like high definition television broadcasts (Maxwell, 1999).

Residential broadband connectivity is now available to consumers in most urban areas and many rural areas throughout North America. Although the Canadian National Broadband Task Force's recommendation to extend broadband access to all Canadians has not been adopted, it is estimated that approximately $40 \%$ of Canadian households that have internet access now have high speed access (Brethour, 2001). Exact figures are hard to come by, but evidence suggests that consumer demand for broadband connectivity is increasing steadily in North America, with Canadian adoption rates currently more than double those in the United States (Buckler, 2001; Luening, 2001).

Despite this growing consumer interest in residential broadband services, there is very little academic research that considers how consumers use broadband networks. Most of the research published to date has focused on technical issues, related primarily to network infrastructure choice and configuration and to mechanisms for deploying content over broadband networks (Bartsch and Auer, 1997; Di Concetto, et al., 1999; Rath, et al., 1997; Zahariadis, et al., 1997). This technical work is essential for the development of broadband networks, but does not offer any insights as to how consumers actually use the services to which they have access, nor does it offer any guidance to providers as to what services are likely to be successful. This paper addresses these shortcomings in the literature by providing a consumer perspective on residential broadband networks and services.

\section{The Netcom Trial: Research Site \& Methodology}

The findings outlined in this paper draw on research conducted during a residential broadband network trial. Planning for the Netcom ${ }^{11}$ trial began in 1993, long before broadband network connectivity was available to consumers on a commercial basis. The trial was operated by a consortium of companies working in a pre-competitive environment. This consortium included hardware, network and content ${ }^{12}$ providers; educational and government organizations; representatives of the local community; and a range of non-profit organizations. The trial was to be user-centred, focusing on understanding what consumers would do when provided with broadband access in their homes.

After a lengthy planning and development stage, the network was commissioned in late 1996. It connected residents in a new subdivision, close to a major Canadian metropolitan area. Approximately 200 users (70\% adults, 30\% children) had access to the network, which was operational between December 1996 and December 1998. Network services included high speed internet access, a community mailing list, music and CD-ROM-based content on demand (served over the network), games and healthcare information.

\footnotetext{
${ }^{11}$ A pseudonym.

${ }^{12}$ In simple terms, the network infrastructure can be thought of as a pipe, or a conduit, and the content is the material that is delivered via this conduit. Residential broadband content can include entertainment and information services, internet access, educational materials, interactive television and video on demand. Content may also be described using the terms 'applications' and 'services'.
} 
There were several research projects conducted at the Netcom trial. The project reported on in this paper focused on understanding how various stakeholders involved in the trial (e.g. network providers, content providers, users) made sense of, or socially constructed, their experiences with the residential broadband network and services, and on how the stakeholders' social constructions of the network influenced the network's success. These questions were approached from an interpretive perspective, using qualitative data gathering techniques that included participant observation, textual analysis and interviews. Data collection started in 1993 and finished in 1999, after the trial ended.

Although the Netcom trial was intended to be a research trial, very little data analysis was done while the network was operational. Few efforts were made by the Netcom consortium, as the group providing the residential broadband network, to understand what had transpired at the trial. Individual consortium members did learn a lot about developing broadband networks, but much of the learning related to technical issues of network deployment. There did not appear to be any systematic identification of issues regarding consumer adoption of broadband networks, thus broadband providers' perspectives on how residential broadband services could be delivered were not challenged in any way. As will be demonstrated below however, there are a number of important lessons to be learned from the Netcom experience. The purpose of this paper is to illustrate these lessons, showing how an understanding of two perspectives on residential broadband deployment can change the existing dominant vision of how residential broadband networks are developed and used.

\section{Netcom Trial Results}

Detailed discussion of this study of the Netcom trial is provided elsewhere (e.g. Middleton, 2000; Middleton, 2002), but the results can be summarized by noting that various stakeholder groups at the Netcom trial had widely divergent interpretations of how residential broadband services might be developed. This conclusion was drawn from an analysis of data from numerous sources, including interviews with network and content providers, focus groups with users, transcripts of the users' community e-mail list, trial documents and field notes. Given the length limitations imposed on this paper, it is difficult to convey the richness of these data. It is noted however that the research sought to identify multiple understandings of residential broadband, from the perspectives of diverse stakeholder groups involved in the trial.

As data were analyzed, it became evident that there were two dominant understandings of residential broadband, one that reflected the user perspective, the other that reflected the perspective of network and content providers ${ }^{13}$. Providers believed that future demand for broadband networks would be driven by a yet to be discovered, bandwidth-hungry 'killer application ${ }^{14}$, yet consumers found value in existing low technology, low bandwidth services. The providers felt that they had failed the consumers, because they had been unable to deliver services that the consumers considered to be valuable. Consumers were pleased with the services they could access, but the providers were not willing to accept that the basic services offered to consumers in the trial were of value to them. A few representative quotes are juxtaposed below to illustrate the two perspectives on the residential broadband services provided at the Netcom trial.

Content is what consumers want to see. They want to see a value proposition. And access alone is not a value proposition. Or it's a value proposition that can't be sustained. I mean

\footnotetext{
${ }^{13}$ It is noted that there was some diversity within each stakeholder group, but the difference in perspectives between the two groups was striking.

14 The term 'killer application', or 'killer app', is used widely to signify a product or service that will drive demand for, or increase sales of, a related product or service. Searches for compelling applications that legitimize or justify the adoption of particular technologies have been recognized in the computer industry for many years (see Bragitikos, 1996; Moore, 1994, on this point).
} 
after a while, consumers want more than just access. ... So what I'm saying is access alone is not a sustainable value proposition. Sooner or later you gotta put compelling content and applications in front of consumers to retain them, to get their loyalty, and they [Netcom] never, they never did that. (Provider perspective, speaker is a manager with a telco involved in the trial.)

Besides the free Internet access we're enjoying, I think what the residents here have become most attached to, is the online community. This is why they are irate at the loss of their wired community, to them it's like ripping apart the neighborhood. I am emersed [sic] in email all day long and should be sick to death of it, but I'm going to miss it too. I think this is something that is not easily measured by the people studying the trial, one because there's no previous data on it, but mostly because it's an emotional attachment. (User perspective, Netcom trial participant.)

If we had services that were truly valuable to the customer I think it would have been a different -- a very different -- story. The problem that we always had and still have until the last day of the trial is that consumers -- we could never really describe to consumers what it is that all of this really meant to them. How does this really make your life better? If you are not a technologist and you are not a visionary and you're not -- you're just a normal hard working nice young family who would rather have air conditioning than another computer, how does this -- how do you really describe to them how valuable this can be or this is? We just never had the opportunity to do it. (Provider perspective, speaker is the real estate developer.)

I have walked around the neighbourhood a lot lately and I have noticed a few things. I have noticed neighbours talking to each other like they have been friends for a long time. I have noticed a closeness that you don't see in many communities. (User perspective, Netcom trial participant.)

My family enjoyed being on the trial. We had acess [sic] to free internet, free health nurse and free games for the kids. We got a good deal on a computer, which we would not own now if it were not for Netcom and we now own a free telephone. We did not buy our house because it was a smart home, but look at the computer system as a bonus that came with our house. We live in a great community, have the chance to talk to all of you through a community e-mail, and have contributed to a worth while study. (User perspective, Netcom trial participant.)

These quotes do not adequately demonstrate user and provider perspectives on residential broadband networks, but do offer a hint of how the two perspectives differ. When these Netcom data are combined with insights from more recent consumer usage of residential communication services, it can be concluded that consumers are interested in connectivity (i.e. the community mailing list, making connections with their neighbours and developing a local community) and access to symmetrical networks where they can control content distribution (e.g. peer to peer file sharing), whereas providers are more interested in delivering broadcast content over asymmetrical networks offering limited options for interactivity (e.g. continued focus on developing services like video on demand).

Drawing on the communications literature, with a particular focus on research on interactivity (Bordewijk and van Kaam, 1986; Jensen, 1998; Rafaeli, 1988), a framework was developed that explained the nature of these differences between the consumer and provider perspectives on residential broadband networks (see Middleton and Oliver, 2002). The differences centre around the assumptions each stakeholder group holds about control of the communication process and control of content.

From the provider perspective, a successful deployment of residential broadband would be one that allowed providers full control of content distribution, meaning for example that consumers might use their broadband network access to view videos or listen to music. This content would 
be offered to consumers by the organization or group of organizations provisioning the broadband network. The providers would allow consumers some measure of interactivity, by making it possible to select specific content for broadcast-type delivery at specific times (e.g. video on demand), but consumers would not have any influence in shaping the content they were receiving. This vision of residential broadband success is described as an 'interactive broadcasting' approach.

For consumers, a successful residential broadband deployment would allow anyone on the network to generate content for consumption by anyone else on the network. From a consumer perspective, allowing all users to be peers on the network would be highly desirable. This would mean that users could control the distribution of content themselves, and contribute to its creation. Users would also want to have control of the communications process, meaning that they could choose when to interact with other users on the network. This vision of broadband success is referred to as a 'fully interactive' approach.

In the Netcom trial, providers and consumers did not appear to understand each others' perspectives on what a successful broadband network would look like. Looking beyond the Netcom trial, the two conflicting visions of success for residential broadband networks persist. It is impossible to know whether users and providers will develop a shared understanding of what form broadband services could take in the future, but it seems reasonable to assume that the provider perspective that defines broadband as a means to deliver interactive broadcasting content will continue to be challenged by users who want full interactivity. This assumption is based on three observations: i) Netcom trial participants found real value in connectivity services; ii) there is increased growth in peer-to-peer (P2P) networking among users of commercial broadband services; and iii) historical patterns (e.g. development of the telephone de Sola Pool, 1977; Fischer, 1992) suggest that communication models based on connectivity are preferred to those based on content delivery.

In the section that follows, implications (for users and providers) of developing broadband networks according to a fully interactive model of service delivery are discussed. It is noted that this model questions many assumptions currently held by service providers, moving them from an environment they can control to an environment controlled by their customers.

\section{Two Visions of Residential Broadband: Implications for Future Broadband Deployments}

When residential broadband success is understood as having two different manifestations, there are a variety of issues broadband providers must understand as they move to extend their services in this area. For instance, recognition by providers of what services users consider to be successful would allow for the development of new services that more closely match user desires for interactivity. From a user perspective, it is beneficial to understand that full interactivity empowers users, freeing them of a dependence on content providers. Table 1 provides an overview of the key points of difference among the two visions of residential broadband success. These points of difference are discussed in more detail below, and the implications for future deployments of residential broadband services are outlined ${ }^{15}$.

\footnotetext{
${ }^{15}$ This purpose of this paper is not to develop testable hypotheses related to future broadband deployments. Rather, the goal here is to highlight the differences between provider and user perspectives on residential broadband, and to outline what these differences imply for future broadband deployments. Given the limited research on consumer usage of broadband services, the implications outlined here can be used as a starting point for future research in this area, research that could eventually specify testable hypotheses related to consumer usage of residential broadband.
} 
Table 1: Implementing Broadband Services - Understanding Two Visions of Success

\begin{tabular}{|l|l|l|}
\hline & Interactive Broadcasting & Full Interactivity \\
\hline Dominant Metaphor & $\bullet$ 'killer app' & $\begin{array}{l}\bullet \text { community } \\
\text { peer-to-peer (P2P) }\end{array}$ \\
\hline Role of Provider & $\begin{array}{l}\text { content \& connectivity } \\
\text { provider }\end{array}$ & $\bullet$ connectivity provider \\
\hline Role of User & $\begin{array}{l}\text { content consumer, low } \\
\text { level interactivity to } \\
\text { request specific content }\end{array}$ & $\bullet$ content provider \\
\hline Control & $\bullet \begin{array}{l}\text { corporate, centralized } \\
\text { potential for corporate } \\
\text { monitoring of users }\end{array}$ & $\bullet$ individual, dispersed \\
\hline Content & $\bullet$ proprietary & $\bullet$ open \\
\hline Network Design & $\bullet$ asymmetrical & $\bullet$ hymmetrical \\
\hline Bandwidth & $\bullet$ high & $\bullet$ e-mail low \\
\hline Key Services & $\bullet \begin{array}{l}\text { video on demand } \\
\text { interactive television }\end{array}$ & $\begin{array}{l}\text { abandon } \text { alliances between } \\
\text { content and network } \\
\text { providers? }\end{array}$ \\
\hline Provider Strategy & $\bullet \begin{array}{l}\text { partnerships between } \\
\text { network and content } \\
\text { providers }\end{array}$ & \\
\hline & &
\end{tabular}

\section{The Dominant Metaphor: Killer Applications vs. Community}

In the Netcom trial, some providers expressed disappointment that no obvious killer application was developed or acquired for users. This sentiment is not unique to the Netcom trial, as many industry participants and observers continue to lament the fact that no killer application has yet emerged for residential broadband. From a provider perspective, this desire for a killer app is entirely reasonable when residential broadband is understood as a broadcast service. Providers need the killer app so that they can deliver value to consumers (in the form of a providercontrolled application like video on demand), because their perspective on residential broadband does not recognize that there is value in connectivity without provider-generated content and services.

But when residential broadband is understood as an interactive service, the perspective on what will drive success changes, as does the vocabulary. Killer apps are replaced by peer-to-peer (P2P) networks, as control of content shifts from provider to user. Value is created for users in basic connectivity, which allows any user to communicate with any other user in a manner that suits both parties. In addition, the Netcom data show that providing connectivity to a group of users with shared interests enables these users to develop an interactive, networked, interest-based community. The Netcom community was united because of their participation in the Netcom trial, their shared experiences in dealing with their real estate developer, and their proximity as neighbours. There are many examples of online communities that have developed on the internet (and its predecessors). Such communities include chat rooms and asynchronous discussion spaces, usenet newsgroups, healthcare support groups, hobbyists' websites, and special interest mailing lists, to name just a few. For users, these sorts of applications provide value, and often do not require high bandwidth connectivity. Providers who understand their customers well will recognize the value in providing peer-to-peer connectivity and opportunities to develop online communities, rather than seeking out the elusive killer application.

Implication 1: Demand for network services will be driven by a desire for connectivity, not by a content-based killer application.

Implication 2: Network providers can increase demand for their services by providing users with support to develop community-based networks and services. 


\section{Role of the Provider}

There is no doubt that some providers will continue to have a crucial role to play in the development of residential broadband. Although consumers are scrambling to take control of content (as the Napster example shows), it is much more difficult for consumers to establish their own network infrastructure. For connectivity providers then, a user-centric view of success does not mean that that their business is threatened. In fact, users are often willing to pay more for connectivity than content, thus the outlook for network connectivity providers is likely to be positive regardless of which vision of success guides future broadband developments. (This is also true for equipment providers, who supply connectivity providers with network infrastructure.) Connectivity providers may want to rethink their corporate partnerships however. In the case that the user-centric perspective becomes dominant in the marketplace, the value of an alliance with a content provider is significantly reduced. Content providers need to consider how they will maintain their market position in a situation where users no longer rely upon such corporate entities to provide content.

Implication 3: The role of the provider will be limited to provision of network services.

\section{Role of the User}

When communication follows a fully interactive pattern, users have much more power than when communication is based on broadcasting or interactive broadcasting models. In a pure broadcast model, consumers are passive recipients of corporate content. Interactive broadcasting allows consumers some input into what content they receive, but they are still a captive audience with no opportunity to generate content of their own. In an interactive setting, users are empowered to generate their own content. This does mean that users need to be more active in their use of communication networks, as they are now the content producers and controllers. As recent developments in file sharing have demonstrated, many users are happy to move from a passive role into a more active one. The content industry recognizes that interactivity poses a serious threat to their way of doing business, and are searching for solutions that would allow content owners to regain control of their intellectual property.

Implication 4: Users will take a more active role in developing content.

\section{Control and Content}

As just noted, in an interactive environment it becomes very difficult to control access to content. In contrast to this new world of individual, distributed control, providers are accustomed to a model where proprietary content is tightly controlled (and its usage is monitored) by centralized corporate entities (as in broadcast television, for example). But a quick scan of the business press (or a discussion with a teenager) will indicate that there is no backtracking, and that providers' ability to maintain tight control over content (and copyright) will continue to erode. It is interesting to note that the power shift, from corporate control to individual control is also occurring elsewhere in the technology industry, with open source software like Linux a prime example.

Implication 5: Control of content will shift from providers to users. It will become increasingly difficult for providers to maintain control over content distribution.

\section{Network Design and Bandwidth}

One particularly important aspect of a move toward interactivity relates to network design. In a pure broadcast environment, content providers and users are connected, but the network infrastructure does not allow for users to provide feedback to providers. Interactive broadcasting 
has changed this setup, allowing users to 'interact' by requesting particular services at particular times, or by following links on web pages. The infrastructure that supports such interactivity is typically asymmetrical in design. This means that the bandwidth from the provider to the user is much higher than the bandwidth from the user 'back' to the provider. This asymmetrical design is present in most cable modem connections, and in the telephone companies' ADSL (asymmetrical digital subscriber line) services. This design is cheaper to implement than a symmetrical one, and made perfect sense in an environment where broadband communication was understood to be a form of interactive broadcasting. With users as passive content receptors, there was no need for high bandwidth from the recipient back to the content broadcaster. There was (and still is) a need for high bandwidth from broadcaster to recipient however, to deliver rich, multimedia, entertainment-type content (e.g. television, movies, music). In a broadcast or interactive broadcasting environment there is no role for a low bandwidth network.

An interactive model of broadband communication changes these perceived wisdoms. As has been noted earlier, in an interactive context, users are peers on the network, so that any user can be a content generator. Users want to be able to send content to the network with the same ease, and at the same speed, that they have been receiving it. Users who swap music and video files, or even exchange vacation photos, would benefit greatly from access to symmetrical networks.

Savvy providers are likely to start differentiating their network offerings. Rather than providing one type of broadband network access for all users, various market niches can be identified. One such niche product is a high bandwidth, symmetrical service, which could command a premium price. But there is also a market for a lower bandwidth service, perhaps at lower cost, that would provide users with connectivity for basic services like e-mail and occasional web browsing. A symmetrical connection is less important in this context, as e-mail and web browsing do not require much upstream bandwidth. However, given a choice, a symmetrical infrastructure is preferred to an asymmetrical one. In addition, although there is little data available to support this suggestion, it is likely that at least some low bandwidth users would be interested in perpetual connectivity (i.e. their low band connection is always on, like current DSL or cable services), at a premium over the standard low bandwidth service. This research indicates that not every low bandwidth user will be interested in moving to higher bandwidth connections, because in an interactive environment, connectivity is often more important than bandwidth.

Implication 6: Users of high speed networks will demand that such networks offer symmetrical bandwidth.

Implication 7: Not all users will demand high bandwidth connectivity. Demand will exist for low bandwidth, perpetually connected networks.

\section{Key Services}

When broadband services are developed according to the interactive broadcasting model, the services that are expected to be popular are entertainment services like video on demand or interactive television. Video on demand has been promised to consumers for many years now (Dholakia, 1996), and there does appear to be some interest in it. It is still not clear however whether video on demand can be offered at a price that is appealing to consumers while still economically viable for providers. In time, it is expected that this service will become available, although it is not clear how widely it will be adopted.

The application that is most widely used in the interactive communication arena is e-mail. This is consistent with the fully interactive model of communication, and as such, its popularity will continue. Low bandwidth text messaging is likely to continue to grow as well, both over the internet (instant messaging) and for wireless devices (SMS - short message service). The other key application in a fully interactive model is peer-to-peer file sharing, for music, video and other multimedia files.

Implication 8: Demand for and usage of high and low bandwidth peer-to-peer services will continue to grow. 


\section{Provider Strategy}

In a broadcast-based model of residential broadband, consumers purchase a suite of services that includes network access and broadband content. Infrastructure providers have not typically had experience in developing broadband content, thus they align with content providers, who could not get their content to consumers without network access. In partnership, the network and content providers offer broadband services to consumers. This partnership is beneficial for both provider groups, as neither could provide all the necessary services on their own. This is the organizing logic that guided the Netcom trial.

When the model for residential broadband success is an interactive one, provider strategies need to be re-assessed. Does it make sense for network providers to align with content providers, if users are more interested in connectivity than content? What should content providers do to maintain their access to consumers? These important issues are ones that will be faced by content and infrastructure providers as users continue to embrace an interactive model of communication.

Implication 9: Alliances between content providers and network providers will become less common.

\section{Conclusions}

What conclusions can be drawn from this discussion? The previous section outlines nine implications that are identified when the differences between provider and user perspectives on residential broadband content and services are understood. It is suggested that the role of broadband providers is likely to be reduced to providing connectivity services only, while users take an increased interest in, and responsibility for, development of content and community.

While there is no firm guarantee that residential broadband networks will develop in the manner suggested above, evidence from the Netcom trial, current broadband deployments and previous communication innovation patterns suggest that this is the likely outcome. Even if there is consumer demand for interactive broadcasting services (e.g. interactive television, video on demand), many of the implications are still valid. It appears that the traditional broadcasting model, where providers had control of content and communication processes, is rapidly disappearing. But providers are not responding in ways that would indicate they understand either the marketplace or the implications of such widespread consumer empowerment.

This raises a very interesting question, one that cannot be answered by the data gathered for this project. The question is "Why do providers appear to be ignoring market forces in their continued search for killer applications to drive broadband demand?". This paper offers no explanation as to why providers appear to be ignoring consumer demand for full interactivity, but the question will be addressed in future research projects.

In the Netcom trial, providers did not conduct their own research, and were not closely monitoring user behaviours. Yet when interviewed, it was apparent that, at least in retrospect, providers did know what consumers were doing on the network. Looking at current commercial deployments of residential broadband, the same provider behaviours appear to hold. For example, all network providers do have user access data that show increasing $\mathrm{P} 2 \mathrm{P}$ traffic, but none are yet offering symmetrical services to their residential users.

There is no doubt that providers are threatened by the consumer behaviours that shift power from network and service providers to consumers. The implications of these behaviours are not reassuring for content or network providers. But there are many indications in the marketplace that future developments will be influenced by consumer preferences for full interactivity, so why are providers acting as if they're unaware of the anticipated trends? Traditional broadcast revenue 
models based on consumers (or advertisers) paying for content will be severely challenged when consumers gain more control of their communication experience. Ignoring this fact will not make it go away.

New business models will be needed to compensate providers for building network services. It is noted however that there is a long standing tradition of paying for connectivity in the telephone market, thus it is likely that a similar model can be applied to residential broadband. Furthermore, any company that hopes to survive as a broadband provider must demonstrate an ability to offer consumers innovative services that meet their needs. Such companies should be able to develop viable business models.

\section{References}

Bartsch, Frank-Reinhard and Auer, Eckart, "Lessons Learned from Multimedia Field Trials in Germany," IEEE Communications Magazine (35:10), 1997, pp. 40-45.

Bordewijk, Jan L and van Kaam, Ben, "Towards a New Classification of Tele-Information Services," Intermedia (14:1), 1986, pp. 16-21.

Bragitikos, Michael, "Just What Will Take the Net from a Novelty to a Necessity?," Wall Street Journal Interactive Edition, 6 December, 1996.

Brethour, Patrick, "Retailers Cautioned to Expect Net Flak," Globe and Mail, 19 November, 2001, pp. B6.

Buckler, Grant, "Studies Forecast Quadrupling of Broadband by 2005," Newsbytes, 13 June, 2001.

de Sola Pool, Ithiel, The Social Impact of the Telephone, MIT Press, Cambridge, MA, 1977.

Dholakia, Ruby Roy, “Taking Movies-on-Demand to Market," In New Infotainment Technologies in the Home: Demand-Side Perspectives, Ruby Roy Dholakia, Norbert Mundorf and Nikhilesh Dholakia (Ed.), Lawrence Erlbaum Associates, Mahwah, NJ, 1996, pp. 75-88.

Di Concetto, Marco, et al., "AMUSE: Advanced Broadband Services Trials for Residential Users," IEEE Network (13:2), 1999, pp. 37-45.

Fischer, Claude S., America Calling: A Social History of the Telephone to 1940, University of California Press, Berkeley, 1992.

Jensen, J. F, "Interactivity: Tracing a New Concept in Media and Communication Studies," Nordicom Review (19:1), 1998, pp. 185-204.

Luening, Erich, "High-Speed Net Subscribers Surpass 9 Million,” CNET News.com, 1 June, 2001.

Maxwell, Kim, Residential Broadband: An Insider's Guide to the Battle for the Last Mile, Wiley Computer Publishing, New York, 1999.

Middleton, Catherine A, "Who Needs a 'Killer App'? Two Perspectives on Content in Residential Broadband Networks," In Proceedings of the 11th Australasian Conference on Information Systems, ACIS, Brisbane, Australia, 2000.

Middleton, Catherine A, "Content and Connectivity: Competing Perspectives on Success in a Residential Broadband Network Trial," Unpublished Doctoral Dissertation, York University, Toronto, 2002.

Middleton, Catherine A and Oliver, Christine, "Connectivity or Content: Two Models of Interactivity in Residential Broadband Networks," Working Paper, Schulich School of Business, York University, Toronto, 2002.

Moore, Steve, "The Killer App Crew," Computerworld, 23 May 1994, pp. 145-146.

National Broadband Taskforce, The New National Dream: Networking the Nation for Broadband Access, Industry Canada, Ottawa, 2001. 
Rafaeli, Sheizaf, "Interactivity: From New Media to Communication," In Advancing Communication Science: Merging Mass and Interpersonal Process, R. P. Hawkins, J. M. Wiemann and S Pingree (Ed.), Sage, Newbury Park, CA, 1988, pp. 110-134.

Rath, Kamlesh, et al., "Interactive Digital Video Networks: Lessons from a Commercial Deployment," IEEE Communications Magazine (35:6), 1997, pp. 70-74.

Zahariadis, Theodore, et al., "Interactive Multimedia Services to Residential Users," IEEE Communications Magazine (35:6), 1997, pp. 61-68. 